This is the version of the article accepted for publication in British Journal of Management published by Wiley: https:// doi.org/10.1111/1467-8551.12025

Accepted version downloaded from SOAS Research Online: http://eprints.soas.ac.uk/21210

\title{
Participative Leadership and the Organizational Commitment of Civil Servants in China: The Mediating Effects of Trust in Supervisor
}

\author{
Miao, Q., A. Newman, G. Schwarz, and L. Xu
}

\begin{abstract}
The present study examines whether participative leadership engenders organizational commitment among Chinese civil servants, and analyzes the mechanisms by which it transmits its effects. Confirmatory factor analysis and structural equation modeling revealed that there was a significant relationship between supervisor-level participative leadership and the affective and normative commitment of subordinates, but no relationship with continuance commitment. Affective trust was identified as the mediator variable underlying the relationship between participative leadership and organizational commitment. We show that participative leadership of supervisors elicits higher levels of trust, and leads subordinates to reciprocate through exhibiting higher levels of organizational commitment. Our study also reveals that Chinese civil servants who accept an unequal distribution of power between supervisors and subordinates typically exhibit lower levels of affective and normative commitment to the organization than those who do not. Our results provide greater support for the deepening of administrative reforms and the dissemination of participative leadership practices in China's new civil service system.
\end{abstract}

Keywords: Participative Leadership; Trust; Organizational Commitment; China 


\section{INTRODUCTION}

There is growing evidence to demonstrate that participative leadership styles engender positive employee work attitudes in the public sector (Kim, 2002; Wright and Kim, 2004). However, most empirical research in this area has been conducted in Western cultures, a context in which participative styles of leadership are common. As of yet, only a small number of recent studies have begun to investigate the effectiveness of participative leadership in China, a cultural context in which authoritarian and command-based styles of leadership have traditionally been practiced and employee involvement has not typically been stressed (Cheng et al., 2004; Tsui et al., 2004).

Although recent empirical studies highlight the growing importance of participative leadership to organizational effectiveness in foreign-invested, privately-owned and even stateowned enterprises (Huang et al., 2006; Huang et al., 2010), there has been limited focus on its relevance in the Chinese civil service, an organizational context characterized by highly centralized structures and significant levels of bureaucracy (Chan and Li, 2007). In addition, there has been no attempt to identify the mechanisms by which participative leadership may engender positive work attitudes, such as organizational commitment, in public sector employees.

This paper seeks to answer two main questions. Does participative leadership engender a positive attitudinal response in Chinese public sector employees, and if so, how does this occur? To answer the first question, we examine the relationship between supervisor's participative leadership and the organizational commitment of their subordinates using data from 239 civil servants in one Chinese province. Understanding the drivers of organizational commitment is important given that it has been shown to relate closely to employee performance in public sector organizations (Balfour and Wechsler, 1996; Moon, 2000; Vandenabeele, 2009). To answer the 
second question, we examine trust in supervisor as an explanatory mechanism underlying the relationship between participative leadership and organizational commitment (Hatzakis, 2009).

We chose to focus on trust in supervisor as it has been shown to be important to Chinese employees given a culture based on Confucianism in which interpersonal relationships and deference to hierarchy are highly valued (Tan and Chee, 2005).

Following Gould-Williams (2003), we use a two-dimensional model and social-exchange theory to examine the impact of trust on employee work outcomes. In contrast, however, we focus on examining the mediating effects of affective and cognitive trust in supervisor, rather than on systems and interpersonal trust which capture an employee's trust in the organization. We chose to focus on affective and cognitive trust as they are associated with competing explanations as to how participative leadership behavior of the supervisor engenders a positive attitudinal response in subordinates.

Affective trust refers to strong emotional ties between the supervisor and the subordinate as they engage in a process of social exchange (McAllister, 1995; Tanghe, Wisse and van der Flier, 2010; Yang and Mossholder, 2010). This type of trust is relational in nature and develops when the subordinate believes that the supervisor is acting with their interests in mind. In contrast, cognitive trust, is more rational, and results from subordinates' personal assessment of their supervisors' salient personal characteristics such as their competence, reliability, and integrity (Ng and Chua, 2006; Schaubroeck, Lam and Peng, 2011). Previous studies investigating the impact of trust on the work attitudes of public sector employees have not distinguished between these two competing dimensions (Cho and Park, 2011; Cho and Ringquist, 2011; Gould-Williams, 2004), thus making it unclear as to whether participative leadership truly 
induces organizational commitment through a social-exchange or economic-exchange mechanism.

The present research contributes to the literature in two main ways. It allows us to establish whether the organizational benefits engendered by participative leadership styles are culturally and institutionally bound, i.e., whether participative leadership is effective in promoting positive work attitudes in the context of the Chinese public sector, given that this theory was initially developed by researchers conducting empirical work in private sector organizations based in Western cultures (Kahai, Sosik and Avolio, 1997). Secondly, it makes a distinct theoretical contribution by enabling an examination of the trust-based mechanisms, affective or cognitive, by which participative leadership elicits organizational commitment amongst Chinese public sector employees, given the cultural and institutional context as previously described. This will allow us to advise leaders in the public sector how to better ensure that their leadership style has the most favorable effect on employee attitudes. This should lead to an improvement in public service provision, which is essential for the future sustainability of the Chinese public sector and the Chinese economic and political system more generally.

This article begins by reviewing the literature on participative leadership and organizational commitment. Following this, hypotheses are developed examining participative leadership's direct and mediated effects on organizational commitment. Next, the methodology is presented and findings described. In the final section, the contribution and implications of the research are discussed, its limitations examined, and suggestions for future research provided. 


\section{THEORETICAL FOUNDATIONS}

\section{Participative Leadership}

Participative leadership refers to a leadership style by which the leader involves subordinates in the process of problem-solving and decision-making (Kahai, Sosik and Avolio, 1997; Somech, 2006). It is an approach to leadership which requires subordinates to take a certain amount of responsibility in the workplace (Sauer, 2011), and therefore shares theoretical underpinnings with frameworks as diverse as distributed leadership theory (Gibb, 1954), shared leadership theory (Carson, Tesluk and Marrone, 2007), and empowering leadership theory (Srivastava, Bartol and Locke, 2006). Participative leaders facilitate subordinate involvement in the decision-making process through encouragement, resource provision, support, and influence. They prefer consultation over direction (Amabile et al., 2004), as well as consensus building, and they exhibit behaviors that allow followers to manage themselves (Wageman, 2001).

\section{Participative Leadership in the Chinese Cultural Context}

Researchers were initially skeptical as to whether Western management practices stressing employee participation could be applied effectively in China, due to the country's high power distance culture which favors top-down authoritarian styles of leadership (Tsui et al., 2004). Power distance refers to extent to which people accept an uneven distribution of power (Yang, Mossholder and Peng, 2007). In high power distance countries such as China, people deem authorities to be superior and elite, thus legitimizing an unequal distribution of power. Although originally conceived for the societal level (Hofstede, 1980), power distance orientation 
has been extensively studied at an individual level within organizations (Clugston et al., 2000). Subordinates who score high on the power distance measure are more likely to accept hierarchical inequality, to defer to their supervisors, and to respect authority (Farh, Hackett and Liang, 2007). For them, solutions are expected to come from supervisors and participation in decision-making is usually considered inappropriate as it questions the supervisor's competency (Kirkman et al., 2009). In contrast, subordinates with a low power distance orientation tend to be less submissive and receptive and are more likely to expect participation in decision-making. These subordinates tend to respond more positively to empowerment, a value associated with participative leaders, than those with higher power distance orientations (Eylon and Au, 1999).

Recent studies indicate the growing incidence of participative leadership styles in the Chinese workplace (Huang et al., 2006). This has resulted from an influx of Western management ideas and changing cultural values as a consequence of China's opening up and reform (Liden, 2012). This should have led to a more widespread acceptance of new leadership styles, although empirical evidence of this acceptance is still lacking. As a result, it is relevant and timely to investigate the extent to which participative leadership styles may influence employee attitudes in such a dynamic environment.

\section{Participative Leadership in the Chinese Institutional Context}

Nations exposed to similar exogenous changes frequently develop similar institutional responses to their environment. Due to China's varying point of departure and its unique contextual factors, no single Western model served as blueprint for China's reforms; rather it designed administrative reforms with 'Chinese characteristics' (Christensen, Dong and Painter, 
2008; Yang, 2007). These administrative reforms shape the environment in which public sector leaders and their subordinates interact, and influence the leadership styles exhibited.

The Communist Party of China (CPC) introduced administrative reforms right after it came to power in 1949, initially with the aim of strengthening the role of the central government (Straussman and Zhang, 2001). As it retained most of the ousted National Party's public sector employees, it controlled them closely. During the Maoist period, the reforms followed a cyclical pattern of centralization and decentralization, in which responsibilities were allocated back and forth between Beijing and subnational units (Ngok and Zhu, 2007). These pendulum swings affected mainly decision-making rights within the government, and not between government and administration. In stark contrast to the 'neutrality' principle of Western systems, the Wilsonian politics-administration dichotomy was never implemented in the People's Republic, as administrative questions were deemed political questions. While the $\mathrm{CPC}$ was willing to reduce its direct political influence over the operational decisions of state-owned enterprises in the postMao period, it was not willing to relinquish control over the public bureaucracy (Chan and $\mathrm{Li}$, 2007; Yang, 2007).

However, in recent decades, the Chinese government has begun to implement reforms aimed at modernizing the public sector. Since Deng Xiaoping initiated the process of opening-up and reform in 1978, six rounds of administrative reforms (1982, 1988, 1993, 1998, 2003, 2008) have been launched, intending to ensure that an arcane public bureaucracy does not restrict economic progress, but instead synchronizes with China's transition from a centrally-planned to a market-based economy (Jing, 2010; Ngok and Zhu, 2007). In 1993, the Provisional Regulations on Civil Servants created a new Chinese civil service system and institutionalized procedures for recruiting, promoting, and rewarding employees (Burns and Wang, 2010; Chan 
and Li, 2007). In 2006, a permanent National Civil Servants Law was introduced with the aim of further improving efficiency and continuing the transition to a meritocracy (Zhang and Zhou, 2010).

The Chinese administrative reforms in the last two decades clearly bear some resemblance to the new public management (NPM) type reforms that were initiated by many Western governments during the same period of time (Christensen, Dong and Painter, 2008; Yang, 2007). Chinese policies, such as attempts to downsize the number of government employees, the decentralization of decision-making rights to subnational units, the marketization of public services, the streamlining of government structures, the creation of single-purpose organizations, more competitive hiring and promotion processes, the introduction of performance-based rewards and the adaptation of private sector best practices, are part of the classic NPM canon (Chan and Li, 2007; Ferlie, Hartley, and Martin, 2003; Ngok and Zhu, 2007; Straussmann and Zhang, 2001). However, other NPM features, such as an emphasis on transparency, have only recently been addressed through the enactment of the Regulation on the Disclosure of Government Information (Xue and Liou, 2012). Empowering subordinates and encouraging supervisors to adopt a participative leadership style in order to improve public services are accepted, only to the extent that this does not interfere with maintaining political control. The simultaneous pursuit of empowerment and control is an apparent contradiction that sets the stage for our study, which investigates whether and how participative leadership may be used by public sector organizations as a tool for eliciting higher levels of organizational commitment amongst the workforce.

\section{Participative Leadership and Organizational Commitment}


The three-component model of organizational commitment developed by Meyer and colleagues (Allen and Meyer, 1990; Meyer, Allen and Smith, 1993) has been widely used when investigating the attitudinal response of employees to facets of their work environment (Chan et al., 2006; Chen and Francesco, 2003; Johnson, Groff and Taing, 2009). It distinguishes among three 'mindsets' which characterize the relationship individuals have with their employing organization. The first, affective commitment, is defined as the extent to which individuals feel attached to, or identify with, their employing organization (van Dierendonck and Jacobs, 2012). Individuals with high levels of affective commitment remain with the organization because they want to do so. The second, normative commitment, refers to individuals' feelings of moral obligation towards the organization. Individuals with high levels of normative commitment will remain with the organization because they feel they ought to do so (Yang and Pandey, 2009). The third, continuance commitment, refers to individuals' economic attachment to the organization. It derives from the perceived costs to the individuals from ending their membership in the organization (Allen and Meyer, 1990).

Social exchange theory has been used in the literature to explain why participative leadership at the supervisor level may induce higher levels of affective and normative organizational commitment in subordinates (Huang et al., 2010). Given that supervisors are seen as the main representatives of the organization, responsible for enforcing organizational policies, social exchange theory asserts that when subordinates are treated well by their supervisor they reciprocate by exhibiting higher levels of organizational commitment (Blau, 1964). Participative leadership may be expected to elicit higher levels of affective commitment in subordinates as employees given an opportunity to participate in decision-making and take greater responsibility over their work will interpret this as a sign that their supervisor wishes to engage in a process of 
social exchange and thus reciprocate accordingly. Likewise, as a result of greater involvement in decision-making, subordinates might also reciprocate by exhibiting greater feelings of obligation towards the organization, and develop higher levels of normative commitment.

While affective and normative commitment can be explained by social exchange theory, continuance commitment has been linked to economic exchange (Shore et al., 2006). Some authors refer to it as 'calculative' commitment, as the profits associated with continued organizational membership are compared to its costs (Park and Rainey, 2007; Penley and Gould, 1988). This instrumental emphasis on the financial aspects of the exchange relationship contrasts sharply with the socio-emotional aspects of the other two commitment types.

According to Allen and Meyer (1990), continuance commitment is high when the prospect of leaving the organization entails significant sacrifice, and the availability of viable alternative employment options is low. The disruption of working relationships has been identified in the literature as a perceived cost of leaving an organization (Meyer, Bobocel and Allen, 1991; Payne and Hoffman, 2005). On leaving their existing organization, subordinates working under a participative leader may have fewer opportunities to participate in decisionmaking in their new job, and therefore lose the ability to demonstrate their talents and undergo on-the-job training. In addition, given that supervisors are responsible for conducting performance appraisals of subordinates and determining career progression within Chinese public organizations, subordinates may also fear losing the career development opportunities that may result from working under a participative leader with whom they have built up a long-term reciprocal understanding with (Liu and Dong, 2012). Discontinuing organizational membership is a sacrifice, as subordinates would have to establish a relationship with a new supervisor in another organization. In their meta-analysis of studies that use the three-component model of 
commitment, Meyer et al. (2002) find that the sacrifice subcomponent of continuance commitment has a stronger impact on turnover intention than the alternative subcomponent. In addition, subordinates who experience participative leadership may also consider fewer employment alternatives (Payne and Hoffman, 2005). These studies suggest that the opportunities for skill development and career progression created by the participative leader will increase the costs of leaving an organization. Thus, participative leadership should lead to higher levels of continuance commitment.

Although a limited number of studies on non-public sector organizations have established a positive relationship between participative leadership and organizational commitment (Huang et al., 2006), there has been limited examination of such relationships in the context of the public sector (Kim, 2002), especially in socialist economies such as China. Based on social and economic exchange theory, we might expect participative leadership to engender higher levels of organizational commitment and thus we hypothesize accordingly:

H1: Participative leadership will be positively related to affective commitment

H2: Participative leadership will be positively related to normative commitment

H3: Participative leadership will be positively related to continuance commitment

\section{Mediating Effects of Trust on the Relationship between Participative Leadership and Organizational Commitment}

Although researchers have examined the relationship between participative leadership and organizational commitment (Huang et al., 2006), limited focus has been placed on identifying the mechanisms underlying it. Trust in supervisor has been put forward by researchers as one mechanism by which the participative leadership behavior might elicit 
positive work outcomes amongst subordinates, given that it measures the quality of the exchange between supervisor and subordinate (Huang et al., 2010). Despite this, previous research investigating the effects of trust on subordinate responses to the leadership behavior of their supervisors has generally not distinguished between its affective and cognitive dimensions (Cho and Park, 2011; Cho and Ringquist, 2011; Dirks and Ferrin, 2002; Gould-Williams, 2003, 2004; Huang et al., 2010). Taking both of these trust types into consideration is particularly important in China, as the Chinese word for trust, xinren, alludes to both the affective and cognitive components of trust, with the first part, xin, referring to a person's sincerity, and the second part, ren, referring to a person's ability.

Affective trust refers to that which develops as both parties in a relationship engage in a reciprocal process of social exchange and develop strong emotional ties with one another (McAllister, 1995; Park, 2012). Chua, Ingram, and Morris (2008) refer to it as 'trust from the heart'. Participative leaders elicit affective trust by showing a willingness to enter into social exchange with their subordinates through the delegation of responsibility and the provision of support and encouragement (Huang et al., 2010). These actions should provide a signal to subordinates that their supervisor has faith in their abilities.

In contrast, cognitive trust refers to 'trust from the head' (Chua, Ingram, and Morris, 2008) as it results from an instrumental and objective evaluation by the subordinate of the supervisor's competence, track record, and reliability (Mayer, Davis and Schoorman, 1995). By allowing subordinates greater involvement in decision-making, participative supervisors engender cognitive trust by influencing the extent to which subordinates perceive them as being competent and fair (Dirks and Ferrin, 2002). 
Affective trust should have stronger mediating effects than cognitive trust on the relationships between participative leadership and both affective and normative organizational commitment for two main reasons. The first results from the fact that affective trust is a deeper and more resilient form of trust than cognitive trust, with affective trust being developed over a longer time frame and resulting from the reciprocated exchange of social benefits between the supervisor and the subordinate (Yang and Mossholder, 2010). Li (2008) uses the term 'strong' trust as a synonym for affective trust. Secondly, the importance of affective trust as a mediator of the impact of participative leadership on the affective and normative commitment of Chinese public sector employees might also be explained by the fact that China is a collective society characterized by high levels of interpersonal relationalism and deference to hierarchy (Farh, Earley and Lin, 1997; Tan and Chee, 2005). In such a context individuals typically put greater effort into developing closer ties with others in the workplace, especially their supervisor, through the reciprocated exchange of favors and benefits (Cheng, Jiang and Riley, 2003; Tan and Chee, 2005). While the protestant ethic of decoupling socio-emotional and instrumental affairs is prevalent in Western countries, combining affective bonds with instrumental exchanges is common in China (Chua, Morris and Ingram, 2009). This is especially the case in public sector organizations due to relatively low employee turnover, which results in more close-knit relationships between individuals. High levels of affective trust with the supervisor should lead to a greater willingness of subordinates to reciprocate by exhibiting greater emotional attachment and feelings of obligation towards the organization. This leads us to the following hypotheses:

H4: Affective trust more strongly mediates the relationship between participative leadership and affective commitment than cognitive trust 
H5: Affective trust more strongly mediates the relationship between participative leadership and normative commitment than cognitive trust

With regard to continuance commitment, which is based on economic rather than social exchange, cognitive trust can be expected to play a more important role than affective trust (Li, 2008). Kanter (1968) even referred to continuance commitment as 'cognitive-continuance commitment'. Cognitive trust involves a calculative assessment that is based on an instrumental inference of the supervisor's competence and reliability (Chua, Ingram and Morris, 2008). This resembles the rational evaluation of the economic costs and benefits of leaving an organization that characterizes continuance commitment. The emotional bond with the supervisor that distinguishes affective trust is absent in this appraisal. Indeed, a meta-analysis about trust has

shown that cognitive trust in supervisor reduces the turnover intentions of subordinates to a greater extent than more general measures of trust comprising items measuring affective trust (Dirks and Ferrin, 2002). Accordingly, we hypothesize:

H6: Cognitive trust more strongly mediates the relationship between participative leadership and continuance commitment than affective trust

\section{METHODS}

\section{Sample}

Self-completion survey questionnaires were used to obtain research data from full-time public sector employees working in government departments in Zhejiang Province, China. Given 
the highly politicized nature of the public sector in China, to reduce the potential that participants answer in a way that they feel their organizations or supervisors would want them to answer, participants were contacted directly to participate in the study rather than through their organization. They were also promised complete anonymity. These steps were taken to minimize the risk of social desirability response bias on the part of participants.

Participants were recruited from a database containing alumni of the College of Public Administration, Zhejiang University, who completed a Master of Public Administration program. From this database, 1000 alumni were invited by e-mail to participate voluntarily in the research study. If they consented to participation, they were sent a link to an online survey. Prior to distribution, the original questionnaire, written in English, was translated into Chinese using the back translation procedure recommended by Brislin (1993). The survey was conducted in three waves separated by two weeks in April and May 2011 to limit the potential of common method bias (Podsakoff et al., 2003). In the first wave, participants were required to rate the participative leadership behavior of their immediate supervisor, in the second wave their trust in their supervisor, and in the third wave their organizational commitment. In total, 239 participants provided responses to all three waves of the study, amounting to a response rate of 24 percent. Male employees accounted for 63.2 percent of our sample with 59 percent of all respondents holding leadership positions. In total, 93.3 percent of our sample was under the age of forty and 77 percent of them had worked under their present supervisor for less than five years.

\section{Measures}

All items are reported in the appendix. 


\section{Participative leadership}

A six-item scale taken from Arnold et al.'s (2000) Empowering Leadership Questionnaire was used to measure participative leadership. This scale has been widely validated in previous research in the Chinese context (Huang et al., 2006; Huang et al., 2010). Respondents were asked to rate the participative leadership behavior of their immediate supervisor using a five-point Likert scale (where $1=$ strongly disagree and $5=$ strongly agree). Cronbach Alpha for this scale was 0.93 .

\section{Affective and cognitive trust}

Two scales containing five and six items taken from McAllister (1995) were used to measure affective and cognitive trust. Respondents were asked to rate their trust in their immediate supervisor on a five-point Likert scale (where $1=$ strongly disagree and $5=$ strongly agree). The Cronbach Alphas for these scales were 0.94 and 0.95 .

\section{Organizational commitment}

Meyer, Allen and Smith's (1993) 18-item three component scale was used to measure organizational commitment. This scale contains six items to measure affective, normative, and continuance commitment. As with the other scales used in this research, respondents were required to rate their commitment on five-point Likert scales (where $1=$ strongly disagree and $5=$ strongly agree). The Cronbach Alphas for these scales were 0.93, 0.87 and 0.79.

\section{Control variables}


Five control variables were included in the study; gender, tenure with one's direct supervisor, age, position in organization, and power distance. Gender was measured as a dummy variable where $1=$ female and $0=$ male. Tenure with supervisor and age were coded as 1 through 8 in time periods of three and five years respectively. Position in organization was coded 1 through 4 representing, non-managerial employees, section managers, department managers, and senior managers. Given that previous research has shown individual-level cultural values to influence employee responses to different facets of their working environment, including leadership behavior, the power distance orientation of subordinates was controlled for using a five-item scale from Donthu and Yoo (1998). This allows us to examine the impact of participative leadership on commitment whilst ruling out the influence of cultural differences between individuals in terms of how they view the importance of hierarchy in the workplace. The alpha coefficient for this scale was 0.78 .

Table 1 reports the means, standard deviations, correlations, and reliability coefficients of all continuous study variables.

Insert Table 1 about here

\section{ANALYSIS AND RESULTS}


Initially, before hypothesis testing was undertaken, the discriminant validity of study variables was ascertained by confirmatory factor analysis using LISREL 8.80 . A seven-factor model was compared with a series of nested models as shown in Table 2. The goodness-of-fit of the seven-factor model was strong, and better than that of other models $\left(X^{2}=1093.46, d f=719\right.$, $\mathrm{RMSEA}=.047, \mathrm{IFI}=.98, \mathrm{CFI}=.98$ ), providing support for the convergent and discriminant validity of study variables. Following this, a Harman's one-factor test was conducted to test for common method bias. This was done by comparing a seven-factor model with that in which all items were loaded onto a single factor. The results show that the one-factor model was significantly weaker than that of the seven-factor model, indicating that common method bias is not a serious problem in this study.

Insert Table 2 about here

Structured equation modeling was then conducted to test hypotheses 1-6. Firstly, the relationships between participative leadership and the three components of organizational commitment were examined to test hypotheses 1 to 3 . As can be seen in Figure 1, only hypotheses 1 and 2 were supported. Although a significantly positive relationship was found between participative leadership and both affective $(\beta=.21 \mathrm{p}<0.05)$ and normative commitment $(\beta=.29 \mathrm{p}<0.01)$, participative leadership was not significantly related to continuance commitment. Out of the control variables, only power distance was negatively related to affective ( $\beta=-.30$ $\mathrm{p}<0.01)$ and normative commitment $(\beta=-.22 \mathrm{p}<0.05)$. None of the other controls were significant. 
Insert Figure 1 about here

Structured equation modeling (SEM) was undertaken using LISREL 8.80 to test the mediation hypotheses 4-6. Following recent best practice (Wood et al., 2010; Zhao, Lynch Jr. and Chen, 2010; Zhu et al., in press) we conducted two sets of SEM, a full mediation model (in which direct effects from participative leadership to the three organizational commitment variables were not included) and a partial mediation model (where direct paths from participative leadership to the three organizational commitment variables were included). The goodness-of-fit indices for the full mediation model were $\left(X^{2}=945.94, d f=552\right.$, RMSEA $=0.055$, IFI $=0.98$, $\mathrm{CFI}=0.98)$ and for the partial mediation model $\left(\mathrm{X}^{2}=943.35, d f=549\right.$, RMSEA $=0.055, \mathrm{IFI}=0.98$, CFI $=0.98)$. The chi-squared for the partial mediation model $\left(X^{2}=943.35, d f=549\right)$ was smaller than that for the full mediation model $\left(\mathrm{X}^{2}=945.94, d f=552\right)$, but not significantly $(\Delta \mathrm{X} 2=2.59$, $\Delta \mathrm{df}=3$, n.s.). Following James et al. (2006), the full mediation model was accepted as the better model as it contains fewer parameters to account for the covariances in the observed data and did not improve fit over the existing model. Table 3 shows the direct and indirect effects of the mediation tests and Figure 2 represents the graphical depiction of the paths of the full mediation model. As the direct paths included in the partial mediation model were not significant, we do not include a graphical representation of the partial mediation model. 
Insert Table 3 about here

Insert Figure 2 about here

Significant path coefficients were found from participative leadership to affective trust $(\beta=.75, \mathrm{p}<0.01)$, from affective trust to affective commitment $(\beta=.37, \mathrm{p}<0.01)$ and from affective trust to normative commitment $(\beta=.26, \mathrm{p}<0.01)$. Although the path coefficient from participative leadership to cognitive trust was significant $(\beta=.60, \mathrm{p}<0.01)$, those between cognitive trust and both affective and normative commitment were insignificant. These findings provide support for hypotheses 4 and 5, indicating that affective trust more strongly mediates the impact of participative leadership on both affective and normative commitment than cognitive trust. However, no support was provided for hypothesis 6 . Neither the paths coefficients from affective trust to continuance commitment nor from cognitive trust to continuance commitment were significant.

Following this, an additional test using structured equation modeling was conducted to provide greater confidence in our findings regarding the strength of the mediated effects. This test is similar to the Sobel (1982) test and has been recommended as a final step when conducting mediation analysis (MacKinnon et al., 2002). The test found that the indirect effects of participative leadership on affective commitment $(\beta=.22, p<0.01)$ and normative commitment $(\beta=.27, p<0.01)$ through affective trust were significant, providing further support for hypotheses 4 and 5. 


\section{DISCUSSION}

The main aim of this study was to examine whether participative leadership generates organizational commitment in the Chinese public sector, and to analyze the mechanisms by which participative leadership transmits its effects on organizational commitment. Our results demonstrate that there is a significant relationship between participative leadership and affective and normative commitment of Chinese public sector employees. These results show that civil servants are susceptible to participative leadership practices. This provides greater support for the dissemination of participative leadership practices in China's new civil service system and the deepening of administrative reforms.

Structural equation modeling identified affective trust as the mechanism underlying the relationship between participative leadership and commitment. Participative leadership behavior signals to public sector employees that their supervisor values their know-how, opinions, and suggestions and that they are interested in their well-being. This elicits higher levels of trust in the supervisor, and leads the subordinates to reciprocate by exhibiting a higher level of organizational commitment (Huang et al., 2010). Hence, affective trust in supervisor is an exchange-based mediator that links participative leadership to affective and normative commitment. The study also revealed that participative leadership was not related to continuance commitment. Our results with regard to continuance commitment are akin to those of Park and Rainey (2007) who found that the leadership style had more of a positive effect on affective commitment than on continuance commitment. 
Our findings about the central role of trust are similar to Gould-Williams (2003) and provide support for Kramer (1995) who showed that trustworthiness of the supervisor is an important factor for lower-level employees, as their position is quite powerless and they routinely confront vulnerabilities in dealing with their organization. As a consequence, Chinese employees frequently search for trustworthy mentors with whom they can develop close relationships, and can approach in time of need (Pearce, 1997). Our results also build support for considering affective trust as 'strong' and cognitive trust as 'weak' form of trust in the Chinese context (Li, 2008).

In our study, power distance was negatively related to both affective and normative commitment. Traditionally, Chinese civil servants were accustomed to their supervisors behaving in an authoritarian rather than a participative manner (Farh, Earley and Lin, 1997). This is often typical for emerging economies, as the more traditional authority structure in the society leads to a higher propensity to accept authoritarianism in the working environment (Chan and Chow, 2007). This tendency was compounded by Chinese Confucian tradition, in which harmony was achieved because everybody knew his or her role. A Chinese adage is "junjun, chenchen, fufu, zizi”, which means that the king ought to behave like a king, the minister like a minister, the father like a father, and the son like a son. A leader, hence, gave orders and subordinates implemented their assigned tasks without questions. It was an unwritten rule that subordinates do not speak out in case they detect flaws in their supervisor's instruction. Our study, however, revealed that Chinese civil servants who accept an unequal distribution of power between supervisors and subordinates typically exhibit lower levels of affective and normative commitment to the organization than those low in power distance. This may be due to the fact that more traditional employees (Farh, Earley and Lin, 1997), i.e., those high in power distance, 
are less satisfied with the changes that have been occurring in the Chinese public sector in recent years, for example the introduction of more performance-based appraisal systems (Liu and Dong, 2012) or the general transformation of government employees from revolutionary cadres into competent technocrats, and thus are less committed to their organizations.

Stazyk, Pandey and Wright (2011) noted the importance of considering the institutional context for understanding organizational commitment. Given the limited availability of monetary incentives within Chinese public sector organizations (Burns and Wang, 2010), increasing organizational commitment through participative practices is an important motivating tool for Chinese public sector employees. Other studies have shown that participative leadership can have positive effects on job satisfaction (Kim, 2002), organizational effectiveness (Macy, Peterson and Norton, 1989), and performance (Bush and Spangler, 1990). Nobel Laureate Friedrich August Hayek famously noted that "practically every individual has some advantage over all others because he possesses unique information of which beneficial use might be made" (1945, p. 521). Chinese leaders will have to overcome their traditional authoritarian practices in order to work together more productively with their subordinates and to take full advantage of their subordinates' tacit knowledge (Hakimi, van Knippenberg and Giessner, 2010). This is necessary to ensure that Chinese public sector organizations are able to adapt to a rapidly changing environment during a period of societal transformation (Tsui et al., 2004). More capable state institutions are beneficial to the Chinese society at-large, as there are positive spillover effects of higher government capabilities, for example to private sector firms operating in China (Pearce et al., 2011). If agencies fail to modernize, public service delivery could be transferred to more efficient private service providers. 
In order to facilitate the movement from authoritarian to more participative leadership styles, Chinese public sector organizations should consider the development of effective training programs for their employees. The Guidelines on the Training of Civil Servants in Chinese Administrative Agencies in 2007 was the first official document acknowledging the importance of training to improve performance (Liu and Dong, 2012). In future training programs, subordinates need to be encouraged to participate in decision-making, express their ideas and views more directly, and engage in constructive controversy. The 2010 Outline of National Median and Long Range Plan for Human Resource Development proposed the advancement of supervisors' leadership skills (Xue and Liou, 2012). Supervisors need to be trained to communicate effectively with their subordinates, be open to their suggestions, to encourage and accept constructive criticism, and to update their management methods (Wong and Tjosvold, 2010). As affective trust in supervisor mediates the impact on commitment, training programs should emphasize the importance of building trust and teach leaders how to do so, e.g., by demonstrating respect and concern for the well-being of their subordinates and by providing them with more guidance and social support (Huang et al., 2010). As the modern Chinese public sector employees are drastically different from the revolutionary cadres of the past, new leadership techniques are essential to develop committed civil servants who can be trusted to utilize their increased discretion to the benefit of their agencies (Arthur, 1994).

\section{Limitations and Suggestions for Future Research}

By using data collected directly from Chinese public sector employees, we demonstrate a positive influence of participative leadership on two dimensions of organizational commitment through affective trust in supervisor. The main limitation of our study results from the fact that it 
included self-report data obtained from a single set of respondents. Although we conducted data collection in three waves to reduce the risk of common method bias, and conducted tests for methodological artifacts, common method bias cannot completely be ruled out. Future research might include supervisor-rated measures of subordinate work outcomes such as job performance to deal with these concerns and truly establish whether high levels of organizational commitment translate into positive behavioral outcomes for Chinese public sector organizations. More objective turnover data might also be gathered to examine the impact of organizational commitment on turnover behavior (Iles, Mabey and Robertson, 1990). Future research might also use control instruments to rule out social desirability effects.

In our article, only one of the potential foci of trust (Yang and Mossholder, 2010), the immediate supervisor, was examined as the emphasis was on studying how the supervisor's participative leadership behavior influenced employee commitment. Future research may analyze the mediating effects of cognitive and affective trust in co-workers and senior management, in addition to trust in supervisor, on subordinate work attitudes (Ruiz et al., 2011).

Public sector organizations are usually considered to be subject to significant administrative constraints, such as rules, regulations, and procedures (Feeney, 2012). The degree of formalization and red tape can be expected to impact the extent to which participative leadership can engender organizational commitment and trust. However, the role of leadership has so far been usually omitted in studies about formalization and red tape (Moynihan, Wright and Pandey, 2012). Participative leadership can be expected to be an appropriate instrument to create commitment only to the extent to which supervisors have some sort of discretionary authority to act upon the suggestions received from their subordinates. In addition, a high degree of formalization could be perceived as a sign of low trust in the employees, which could prompt 
them to reciprocate with lower organizational commitment (Li et al., 2011). Future research might analyze the impact of participative leadership in the context of the literature pertaining to formalization (Bozeman and Scott, 1996; Walsh and Dewar, 1987) and red tape (Brewer and Walker, 2010; Pandey and Scott, 2002) in order to examine how much commitment and trust are affected by codified, excessive, or dysfunctional rules.

We also call for more outcome-based research, as few studies investigate whether participative leadership ultimately helps to foster not only more committed employees but also better public services in China.

As research on the psychological mechanisms underlying the relationship between participative leadership and follower work attitudes is reaching an advanced stage, more investigation should be done to examine organizational contexts in which followers respond more positively to the exercise of participative leadership. In addition, scholars might conduct further research to identify the characteristics of individuals that make them more susceptible to the influence of participative leadership, especially in hierarchical and collectivistic cultures such as China.

Finally, future work may be conducted at the cross-cultural and cross-sectorial level to further explore the extent to which cultural and institutional differences impact the mechanisms by which participative leadership influences organizational commitment. 


\section{APPENDIX}

\section{Participative Leadership}

My supervisor encourages work group members to express ideas/suggestions.

My supervisor listens to my work group's ideas and suggestions.

My supervisor uses my work group's suggestions to make decisions that affect us.

My supervisor gives all work group members a chance to voice their opinions.

My supervisor considers my work group's ideas when he/she disagrees with them.

My supervisor makes decisions that are based only on his/her own ideas.

\section{Affective Trust}

We have a sharing relationship. We can both freely share our ideas, feelings, and hopes.

I can talk freely to this individual about difficulties I am having at work and know that (s)he will want to listen.

We would both feel a sense of loss if one of us was transferred and we could no longer work together.

If I shared my problems with this person, I know (s)he would respond constructively and caringly.

I would have to say that we have both made considerable emotional investments in our working relationship.

\section{Cognitive Trust}

This person approaches his/her job with professionalism and dedication.

Given this person's track record, I see no reason to doubt his/her competence and preparation for the job.

I can rely on this person not to make my job more difficult by careless work.

Most people, even those who aren't close friends of this individual, trust and respect him/her as a co-worker.

Other work associates of mine who must interact with this individual consider him/her to be trustworthy.

If people knew more about this individual and his/her background, they would be more concerned and monitor his/her performance more closely.

\section{Affective Commitment}

I would be very happy to spend the rest of my career with this organization.

I really feel as if this organization's problems are my own.

I do not feel a strong sense of "belonging" to my organization.

I do not feel "emotionally attached" to this organization.

I do not feel like "part of the family" at my organization.

This organization has a great deal of personal meaning for me.

\section{Normative Commitment}

I do not feel any obligation to remain with my current employer.

Even if it were to my advantage, I do not feel it would be right to leave my organization now.

I would feel guilty if I left my organization now.

This organization deserves my loyalty. 
I would not leave my organization right now because I have a sense of obligation to the people in it.

I owe a great deal to my organization.

\section{Continuance Commitment}

Right now, staying with my organization is a matter of necessity as much as desire.

It would be very hard for me to leave my organization right now, even if I wanted to.

Too much of my life would be disrupted if I decided I wanted to leave my organization now. I feel that I have too few options to consider leaving this organization.

If I had not already put so much of myself into this organization, I might consider working elsewhere.

One of the few negative consequences of leaving this organization would be the scarcity of available alternatives. 


\section{REFERENCES}

Allen, N. J. and J. P. Meyer (1990). 'The measurement and antecedents of affective, continuance and normative commitment to the organization', Journal of Occupational Psychology, 63, pp. $1-18$.

Amabile, T. M. , E. A. Schatzel, G. B. Moneta and S. J. Kramer (2004). 'Leader behaviors and the work environment for creativity: Perceived leader support', Leadership Quarterly, 15, pp. 5-32.

Arnold, J. A., S. Arad, J. A. Rhoades and F. Drasgow (2000). 'The empowering leadership questionnaire: The construction and validation of a new scale for measuring leader behaviors', Journal of Organizational Behavior, 21, pp. 249-269.

Arthur, J. B. (1994). 'Effects of human resource systems on manufacturing performance and turnover', Academy of Management Journal, 37, pp. 670-87.

Balfour, D. L. and B. Wechsler (1996). 'Organizational commitment: Antecedents and outcomes in public organizations', Public Productivity and Management Review, 19, pp. 256-277.

Baron, R. M. and D. A. Kenny (1986). 'The moderator-mediator variable distinction in social psychological research: Conceptual, strategic, and statistical considerations', Journal of Personality and Social Psychology, 51, pp. 1173-1182.

Becker, H. S. (1960). 'Notes on the concept of commitment', American Journal of Sociology, 66, pp. $32-42$.

Blau, P. (1964). Exchange and Power in Social Life. New York: Wiley.

Bozeman, B. and P. Scott (1996). 'Bureaucratic red tape and formalization: Untangling conceptual knots', American Review of Public Administration, 26, pp. 1-17. 
Brewer, G. A. and R. M. Walker (2010). 'The impact of red tape on governmental performance: An empirical analysis', Journal of Public Administration Research and Theory, 20, pp. $233-257$.

Brislin, R. (1993). Understanding Culture's Influence on Behavior. Fort Worth, TX: Harcourt Brace Publishers.

Burns, J. P. and X. Wang (2010). 'Civil service reform in China: Impacts on civil servants' behaviour', China Quarterly, 201, pp. 58-78.

Bush, K. and R. Spangler (1990). 'The effects of quality circles on performance and promotions', Human Relations, 43, pp. 573-582.

Carson, J. B., P. E. Tesluk, and J. A. Marrone (2007). 'Shared leadership in teams: An investigation of antecedent conditions and performance', Academy of Management Journal, 50, pp. 1217-1234.

Chan, H. S. and K. W. Chow (2007). 'Public management policy and practice in Western China', American Review of Public Administration, 37, pp. 479-498.

Chan, H. S. and E. S. Li (2007). 'Civil service law in the People's Republic of China: A return to cadre personnel management', Public Administration Review, 67, pp. 383-398.

Chen, Z. X. and A. M. Francesco (2003). 'The relationship between the three components of commitment and employee performance in China', Journal of Vocational Behavior, 62, pp. $490-510$.

Cheng, B. S., L. F. Chou, T. Y. Wu, M. P. Huang and J. L. Farh (2004). 'Paternalistic leadership and subordinate response: Establishing a leadership model in Chinese organizations', Asian Journal of Social Psychology, 7, pp. 89-117. 
Cheng, B. S., D. Y. Jiang, and J. H. Riley (2003). 'Organizational commitment, supervisory commitment, and employee outcomes in the Chinese context: Proximal hypothesis or global hypothesis?', Journal of Organizational Behavior, 24, pp. 313-34.

Cho, Y. J. and H. Park (2011). 'Exploring the relationships among trust, employee satisfaction, and organizational commitment', Public Management Review, 13, pp. 551-573.

Cho, Y. J. and E. J. Ringquist (2011). 'Managerial trustworthiness and organizational outcomes', Journal of Public Administration Research and Theory, 21, pp. 53-86.

Chua, R. Y. J., P. Ingram and M. W. Morris (2008). 'From the head and the heart: Locating cognition- and affect-based trust in managers' professional networks', Academy of Management Journal, 51, pp. 436-452.

Chua, R. Y. J., M. W. Morris, and P. Ingram (2009). 'Guanxi vs networking: Distinctive configurations of affect- and cognition-based trust in the networks of Chinese vs American managers', Journal of International Business Studies, 40, pp. 490-508.

Christensen, T., L. Dong and M. Painter (2008). 'Administrative reform in China's central government - how much 'learning from the West'?', International Review of Administrative Sciences, 74, pp. 351-371.

Clugston, M., P. J. Howell and P. W. Dorfman (2000). 'Does cultural socialization predict multiple bases and foci of commitment?' Journal of Management, 26, pp. 5-30.

Dirks, K. T. and D. L. Ferrin (2002). 'Trust in leadership: Meta-analytic findings and implications for research and practice', Journal of Applied Psychology, 87, pp. 611-628.

Donthu, N. and B. Yoo (1998). 'Cultural influences on service quality expectations', Journal of Services Research, 1, pp. 178-185. 
Eylon, D. and K. Y. Au (1999). 'Exploring empowerment: Cross-cultural differences along the power distance dimension', International Journal of Intercultural Relations, 23, pp. 373385.

Farh, J. L., P. C. Earley and S. C. Lin (1997). 'Impetus for action: A cultural analysis of justice and organizational citizenship behavior in Chinese society', Administrative Science Quarterly, 42, pp. 421-444.

Feeney, M. K. (2012). 'Organizational red tape: A measurement experiment', Journal of Public Administration Research and Theory, 22, pp. 427-444.

Ferlie, E., J. Harley and S. Martin (2003). 'Changing public service organizations: Current perspectives and future prospects', British Journal of Management, 14, pp. S1-S14.

Gibb, C. A. (1954). 'Leadership'. In G. Lindzey (ed.), Handbook of Social Psychology, pp. 877-917. Reading, MA: Addeson-Wesley.

Gould-Williams, J. (2003). 'The importance of HR practices and workplace trust in achieving superior performance: A study of public-sector organizations', International Journal of Human Resource Management, 14, pp. 28-54.

Gould-Williams, J. (2004). 'The effects of 'high commitment' HRM practices on employee attitude: The views of public sector workers', Public Administration, 82, pp. 63-81.

Hayek, F. A. (1945). 'The use of knowledge in society', American Economic Review, 35, pp. $519-530$.

Hakimi, N., D. van Knippenberg and S. Giessner (2010). 'Leader empowering behaviour: The leader's perspective', British Journal of Management, 21, pp. 701-716.

Hatzakis, T. (2009). 'Towards a framework of trust attribution styles', British Journal of Management, 20, pp. 448-460. 
Huang, X., J. Iun, A. Liu and Y. Gong (2010). 'Does participative leadership enhance work performance by inducing empowerment or trust? The differential effects on managerial and non-managerial subordinates', Journal of Organizational Behavior, 31, pp. 122-143.

Huang, X., K. Shi, Z. Zhang and Y. L. Cheung (2006). 'The impact of participative leadership behavior on psychological empowerment and organizational commitment in Chinese state-owned enterprises: The moderating role of organizational tenure', Asia-Pacific Journal of Management, 23, pp. 345-367.

James, L. R., S. A. Mulaik, \& J. M. Brett (2006). 'A tale of two methods', Organizational Research Methods, 9, pp. 233-244.

Javidan, M., P. W. Dorfman, M. S. de Luque and R. J. House, (2006). 'In the eye of the beholder: Cross-cultural lessons in leadership from project GLOBE', Academy of Management Perspectives, 20, pp. 67-90.

Jing, Y. (2010). 'History and context of public administration in Mainland China'. In E. Berman, M. J. Moon and H. Choi (eds.), Public Administration in East Asia: Mainland China, Japan, South Korea, and Taiwan, pp. 33-54. New York: Taylor and Francis.

Johnson, R. E., K. W. Groff and M. U. Taing (2010). 'Nature of the interactions among organizational commitments: Complementary, competitive or synergistic?', British Journal of Management, 20, pp. 431-447.

Kahai, S. S., J. J. Sosik and B. J. Avolio (1997). 'Effects of leadership style and problem structure on work group process and outcomes in an electronic meeting system environment', Personnel Psychology, 50, pp. 121-146.

Kanter, R. M. (1968). 'Commitment and social organization: A study of commitment mechanisms in utopian communities', American Sociological Review, 33, pp. 499-517. 
Kim, S. (2002). 'Participative management and job satisfaction: Lessons for management leadership', Public Administration Review, 62, pp. 231-241.

Kirkman, B. L., K. B. Lowe and C. B. Gibson (2006). 'A quarter century of culture's consequences: A review of empirical research incorporating Hofstede's cultural value framework', Journal of International Business Studies, 37, pp. 285-320.

Kirkman, B. L., G. Chen, J. L. Farh, Z. X. Chen and K. B. Lowe (2009). 'Individual power distance orientation and follower reactions to transformational leaders: A cross level, crosscultural examination', Academy of Management Journal, 52, pp. 744-764.

Kramer, R. M. (1995). 'Divergent realities and convergent disappointments in the hierarchic relation: Trust and the intuitive auditor at work'. In R. M. Kramer and R. M. Tyler (eds), Trust in Organizations: Frontiers of Theory and Research, pp. 216-245. Thousand Oaks, CA: Sage.

Li, P. P. (2008). 'Toward a geocentric framework of trust: An application to organizational trust', Management and Organization Review, 4, pp. 413-439.

Li, P. P., Y. Bai and Y. Xi (2011). 'The contextual antecedents of organizational trust: a multidimensional cross-level analysis', Management and Organization Review, 8, pp. $371-396$.

Liden, R. C. (2012). 'Leadership research in Asia: A brief assessment and suggestions for the future', Asia Pacific Journal of Management, 29, pp. 205-212.

Liu, X. and K. Dong (2012). 'Development of the civil servants' performance appraisal system in China: Challenges and improvements', Review of Public Personnel Administration, 32, pp. 149-168. 
Iles, P., C. Mabey and I. Robertson (1990). 'HRM practices and employee commitment: Possibilities, pitfalls and paradoxes', British Journal of Management, 1, pp. 147-157.

MacKinnon, D. P., C. M. Lockwood, J. M. Hoffman, S. G. West and V. A. Sheets (2002). 'Comparison of methods to test mediation and other intervening variable effects', Psychological Methods, 7, pp. 83-104.

Macy, B. A., M. F. Peterson and L. W. Norton (1989). 'A test of participation theory in a work redesign field setting: Degree of participation and comparison site contrasts', Human Relations, 42, pp. 1095-1165.

Mayer, R., C. J. H. Davis and F. D. Schoorman (1995). 'An integrative model of organizational trust', Academy of Management Review, 20, pp. 709-734.

McAllister, D. J. (1995). 'Affect- and cognition-based trust as foundations for interpersonal cooperation in organizations', Academy of Management Journal, 38, pp. 24-59.

Meyer, J. P., N. J. Allen and C. A. Smith (1993). 'Commitment to organizations and occupations: extension and test of a three-component conceptualization', Journal of Applied Psychology, 78, pp. 538-555.

Moon, M. J. 2000. 'Organizational commitment revisited in new public management: Motivation, organizational culture, sector, and managerial level', Public Performance and Management Review, 24, pp. 177-194.

Ng, K. Y. and R. Y. J. Chua (2006). 'Do I contribute more when I trust more? Differential effects of cognition- and affect-based trust', Management and Organization Review, 2, pp. 43-66. 
Ngok, K. and G. Zhu (2007). 'Marketization, globalization and administrative reform in China: A zigzag road to a promising future', International Review of Administrative Sciences, 73, pp. $217-233$.

Pandey, S. K. and P. G. Scott (2002). 'Red tape: A review and assessment of concepts and measures', Journal of Public Administration Research and Theory, 12, pp. 553-580.

Park, S. M. (2012). 'Toward the trusted public organization: Untangling the leadership, motivation, and trust relationship in U. S. federal agencies', American Review of Public Administration, 42, pp. 562-590.

Park, S. M. and H. G. Rainey (2007). 'Antecedents, mediators, and consequences of affective, normative, and continuance commitment: Empirical tests of commitment effects in federal agencies', Review of Public Personnel Administration, 27, pp. 197-226.

Pearce, J. L., K. M. Xin, Q. J. Xu and A. N. Rao (2011). 'Manager's context: How government capability affects managers', British Journal of Management, 22, pp. 500-516.

Pearce, R. J. (1997). 'Towards understanding joint venture performance and survival: A bargaining and influence approach to transaction cost theory', Academy of Management Review, 22, pp. 203-35.

Penley, L. E. and S. Gould (1988). 'Etzioni's model of organizational involvement: A perspective for understanding commitment to organizations', Journal of Organizational Behavior, 9, pp. 43-59.

Podsakoff, P. M., S. B., MacKenzie, J. Y. Lee and N. P. Podsakoff (2003). 'Common method biases in behavioural research: A critical review of the literature and recommended remedies', Journal of Applied Psychology, 88, pp. 879-903. 
Sauer, S. J. (2011). 'Taking the reins: The effects of new leader status and leadership style on team performance', Journal of Applied Psychology, 96, pp. 574-587.

Schaubroeck, J., S. K. Lam and A. C. Peng (2011). 'Cognition-based and affect-based trust as mediators of leader behavior influences on team performance', Journal of Applied Psychology, 96, pp. 863-871.

Shore, L. M., L. E. Tetrick, P. Lynch and K. Barksdale (2006). 'Social and economic exchange: Construct development and validation', Journal of Applied Social Psychology, 36, pp. $837-867$.

Sobel, M. E. (1982). 'Asymptotic confidence intervals for indirect effects in structural equation models'. In S. Leinhart (ed.), Sociology Methodology, pp. 290-391. San Francisco: Jossey-Bass.

Somech, A. (2006). 'The effects of leadership style and team process on performance and innovation in functionally heterogeneous teams', Journal of Management, 32, pp. $132-157$.

Srivastava, A., K. M. Bartol and E. A. Locke (2006). 'Empowering leadership in management teams: Effects on knowledge sharing, efficacy, and performance', Academy of Management Journal, 49, pp. 1239-1251.

Stazyk, E. C., S. K. Pandey and B. Wright (2011). 'Understanding affective organizational commitment: The importance of institutional context', American Review of Public Administration, 41, pp. 603-624.

Straussmann, J. D. and M. Zhang (2001). 'Chinese administrative reforms in international perspective', International Journal of Public Sector Management, 14, pp. 411-422. 
Tan, H. H. and D. Chee (2005). 'Understanding interpersonal trust in a Confucian-influenced society. An exploratory study', International Journal of Cross Cultural Management, 5, pp. 197-212.

Tanghe, J., B. Wisse and H. van der Flier (2010). 'The formation of group affect and team effectiveness: The moderating role of identification', British Journal of Mangement, 21. pp. $340-358$.

Tsui, A. S., C. B. Schoonhoven, M. W. Meyer, C. M. Lau and G. T. Milkovich (2004). 'Organization and management in the midst of societal transformation: The People's Republic of China', Organization Science, 15, pp. 133-144.

Vandenabeele, W. (2009). 'The mediating effect of job satisfaction and organizational commitment on self-reported performance: More robust evidence of the PSMperformance relationship', International Review of Administrative Sciences, 75, pp. 11-34.

Van Dierendonck, D. and G. Jacobs (2012). 'Survivors and victims, a meta-analytical review of fairness and organizational commitment after downsizing', British Journal of Management, 23, pp. 96-109.

Wageman, R. (2001). 'How leaders foster self-managing team effectiveness: Design choices versus hands-on coaching', Organization Science, 12, pp. 559-577.

Walsh, J. P. and R. D. Dewar (1987). 'Formalization and the organizational life cycle', Journal of Management Studies, 24, pp. 215-231.

Wong, A. and D. Tjosvold (2010). 'Guanxi and conflict management for effective partnering with competitors in China', British Journal of Management, 21, pp. 772-788. 
Wood, R. E., J. S. Goodman, N. Beckmann and A. Cook (2010). 'Mediation testing in management research: A review and proposals', Organizational Research Methods, 11, pp. 270-295.

Wright, B. and S. Kim (2004). 'Participation's influence on job satisfaction: The importance of job characteristics', Review of Public Personnel Administration, 24, pp. 18-40.

Xue, L. and K. T. Liou (2012). 'Government reform in China: Concepts and reform cases', Review of Public Personnel Administration, 32, pp. 115-133.

Yang, J. and K. W. Mossholder. (2010). 'Examining the effects of trust in leaders: A bases-andfoci approach', Leadership Quarterly, 21, pp. 50-63.

Yang, K. (2007). 'China's 1998 administrative reform and new public management: Applying a comparative framework', International Journal of Public Administration, 30, pp. $1371-1392$.

Yang, K. and S. K. Pandey (2009). 'How do perceived political environment and administrative reform affect employee commitment?', Journal of Public Administration Research and Theory, 19, pp. 335-360.

Zhang, M. and W. Zhou (2010). 'Civil service reforms in Mainland China'. In E. Berman, M. J. Moon and H. Choi (eds.), Public Administration in East Asia: Mainland China, Japan, South Korea, and Taiwan, pp. 145-164. New York: Taylor and Francis.

Zhao, X., J. G. Lynch Jr, and Q. Chen (2010). 'Reconsidering Baron and Kenny: Myths and truths about mediation analysis. Journal of Consumer Research, 37, pp. 197-206.

Zhu, W., A. Newman, Q. Miao and G. Hooke (in press). 'Revisiting the mediating role of trust on transformational leadership effects: Do different types of trust make a difference?' Leadership Quarterly. 
Table 1: Descriptive Statistics, Reliability Coefficients and Correlations amongst Main Study Variables

\begin{tabular}{|c|c|c|c|c|c|c|c|c|c|}
\hline Variable & Mean & S.D. & 1 & 2 & 3 & 4 & 5 & 6 & 7 \\
\hline $\begin{array}{l}\text { 1. Participative } \\
\text { leadership }\end{array}$ & 3.26 & .87 & (.93) & & & & & & \\
\hline 2. Affective trust & 3.12 & 1.03 & $.68^{* *}$ & $(.94)$ & & & & & \\
\hline 3. Cognitive trust & 3.48 & .99 & $.53 * *$ & $.73 * *$ & $(.95)$ & & & & \\
\hline $\begin{array}{l}\text { 4. Affective } \\
\text { commitment }\end{array}$ & 3.26 & .93 & $.36^{* *}$ & $.42^{* *}$ & $.29 * *$ & $(.93)$ & & & \\
\hline $\begin{array}{l}\text { 5. Normative } \\
\text { commitment }\end{array}$ & 2.83 & .82 & $.37^{* *}$ & $.40^{* *}$ & $.35^{* *}$ & $.65 * *$ & $(.87)$ & & \\
\hline $\begin{array}{l}\text { 6. Continuance } \\
\text { commitment }\end{array}$ & 2.94 & .85 & .08 & .10 & $.24 * *$ & $.14^{*}$ & $.18^{* *}$ & (.79) & \\
\hline 7. Power distance & 2.97 & .78 & $-.54 * *$ & $-.54 * *$ & $-.41 * *$ & $-.38 * *$ & $-.34 * *$ & .03 & $(.78)$ \\
\hline
\end{tabular}

Table 2: Confirmatory Factor Analysis

\begin{tabular}{llllll}
\hline Model & $\mathbf{X}^{2}$ & $\mathbf{d} f$ & $\mathbf{I F I}$ & $\mathbf{C F I}$ & RMSEA \\
\hline $\begin{array}{l}\text { Seven-factor model } \\
\begin{array}{l}\text { Six-factor model: affective and } \\
\text { cognitive trust combined }\end{array}\end{array}$ & 1093.46 & 719 & .98 & .98 & .05 \\
$\begin{array}{l}\text { Five-factor model: affective, } \\
\text { normative and continuance } \\
\begin{array}{l}\text { commitment combined } \\
\text { One-factor model }\end{array}\end{array}$ & 1665.47 & 725 & .96 & .96 & .07 \\
\hline
\end{tabular}

IFI, is the incremental fit index; CFI, the comparative fit index; and RMSEA, the root-meansquare error of approximation. 
Table 3: Structural Equation Path Coefficients $(n=239)$

\begin{tabular}{|c|c|c|}
\hline & \multicolumn{2}{|c|}{$\begin{array}{l}\text { Standardized path coefficients and T-values (in } \\
\text { parentheses) }\end{array}$} \\
\hline & $\begin{array}{l}\text { Model } 1 \\
\text { (Full mediation) }\end{array}$ & $\begin{array}{l}\text { Model 2 } \\
\text { (Partial mediation) }\end{array}$ \\
\hline PL - Affective commitment & & $.14(1.07)$ \\
\hline PL - Normative commitment & & $.21(1.26)$ \\
\hline PL - Continuance commitment & & $-.01(-0.06)$ \\
\hline $\mathrm{PL}-$ Affective trust & $.74\left(11.33^{* *}\right)$ & $.74\left(11.31^{* *}\right)$ \\
\hline $\mathrm{PL}-$ Cognitive trust & $.59\left(8.85^{* *}\right)$ & $.59(8.81 * *)$ \\
\hline $\begin{array}{l}\text { Affective trust - Affective } \\
\text { commitment }\end{array}$ & $.50(7.13 * *)$ & $.38(3.49 * *)$ \\
\hline $\begin{array}{l}\text { Cognitive trust - Affective } \\
\text { commitment }\end{array}$ & $-.05(-.81)$ & $-.06(-.70)$ \\
\hline $\begin{array}{l}\text { Affective trust - Normative } \\
\text { commitment }\end{array}$ & $.37(5.52 * *)$ & $.21(1.66)$ \\
\hline $\begin{array}{l}\text { Cognitive trust - Normative } \\
\text { commitment }\end{array}$ & $.13(1.91)$ & $.11(1.20)$ \\
\hline $\begin{array}{l}\text { Affective trust - Continuance } \\
\text { commitment }\end{array}$ & $-.17(-1.47)$ & $-.17(-1.09)$ \\
\hline $\begin{array}{l}\text { Cognitive trust - Continuance } \\
\text { commitment }\end{array}$ & $.38(1.60)$ & $.38(1.49)$ \\
\hline
\end{tabular}

